\title{
Notas sobre la historia de la Sociología peruana (1896-1930)
}

\section{RESUMEN}

Este trabajo, inicial, sobre la Historia de la Sociología Peruana (1896-1930), forma parte de un Proyecto mayor de investigación de reconstrucción teórica de la evolución y desarrollo de la sociología peruana. Cubre la etapa pre-sociológica o de antecedentes de las ideas y teorías sociológicas, la etapa del desarrollo de la Cátedra Universitaria o de la enseñanza de la Sociología General y la llamada Sociología Nacional (denominada después, Sociología Peruana) y, la etapa del desarrollo científico y profesional de la sociología. Esta última etapa, constituye un gran reto o tarea por desarrollar, haciendo un balance, evaluativo y crítico, de su dinámica institucional.

Palabras clave: Cátedra universitaria, enfoques teóricos, fenómenos sociales, dimensiones sociales, métodos de investigación social

\section{Notes on the history of Peruvian sociology (1896-1930)}

\section{ABSTRACT}

The history of Peruvian Sociology (1896-1930), is part of a major research project about a theoretical reconstruction of both evolution and development in Peruvian sociology. The investigation covers the pre-sociological period also known as the sociological background phase of ideas and theories, the development of the university professor or the general sociology teaching phase, the so-called National Sociology phase named later as Peruvian Sociology, and finally the phase of scientific and professional development of sociology. This last period is a greater challenge to investigate making an evaluative and critical stocktaking of its institutional dynamics.

KEYwORDs: University professor, theoretical approaches, social phenomena, social dimensions, social research methods 


\section{Introducción}

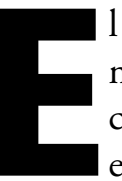
1 presente trabajo surgió como necesidad de mejorar y ampliar nuestro conocimiento relacionado al curso denominado "Sociología en el Perú", que se dicta en Facultad de Ciencias Sociales de la Universidad Nacional Mayor de San Marcos. Nos pareció insuficiente los estudios realizados hasta la fecha. Sin embargo, el mérito de estos radica en el esfuerzo por presentarnos en forma panorámica el desarrollo histórico de nuestra disciplina en el Perú. Principalmente de aquella sociología que corresponde a su etapa fundacional.

$\mathrm{Al}$ respecto, cabe mencionar los trabajos pioneros de Roberto Agramonte ("Sociología académica peruana”, en Sociología latinoamericana, 1963), Héctor Ballón Lozada (Ensayos de Sociología, 1990, y La Sociología en Arequipa, 1971), Alfredo Hernández Urbina ("La Sociología en el Perú", en Compendio de Sociología peruana, 1976), Aníbal Ismodes Cairo ("La Sociología en el Perú", en Lecciones de Introducción a la Sociología, 1959), Roberto Mac Lean y Estenós ("Sociología latinoamericana”, en Sociología integral, t. 1, 1951), Bruno Podestá (Para una historia de la Sociología en el Perú. Un balance crítico, 1978 ), José Pareja Paz-Soldán (Sociología, 1963), Alfredo Poviña ("La Sociología en el Perú", en Historia de la Sociología latinoamericana, 1941 y Nueva Historia de la Sociología latinoamericana, 1959), Aníbal Quijano (Imagen y tareas del sociólogo en la sociedad peruana, 1965), Augusto Salazar Bondy (Historia de las ideas en el Perú contemporáneo, 1967), Héctor Salazar Zapatero (Las alternativas históricas en el pensamiento social del Perú de fines del siglo XIX, 1992) y Guillermo Rochabrún ("Sociología y sociedad en el Perú: un esbozo histórico", en Estudios de historia de la ciencia en el Perú, 1986).

El análisis crítico de estos estudios valiosos e importantes, nos ha permitido seguir el proceso de evolución y desarrollo de la Sociología en y del Perú. Es evidente que todavía quedan, a pesar de los esfuerzos realizados en materia de investigación, una serie de temas y problemas por resolver. Sin duda, nuestro trabajo es un pequeño aporte respecto a los anteriores estudios. Pero falta aún muchos aspectos por investigar y profundizar este tema. Abrigamos la esperanza y tenemos la firme convicción de que el presente estudio tendrá sus continuadores. Creemos que es necesario no sólo rescatar y develar los aspectos histórico-dialécticos de la sociología para lograr nuestra razón científica e identidad sociológica; sino, también, para relievar los esfuerzos de creatividad y originalidad del pensamiento sociológico develando los enigmas de los complejos y multifacéticos procesos y fenómenos sociales que acontecen en la sociedad concreta.

Nuestra tesis es que la ciencia sociológica que se desarrolla en el Perú y en América Latina es científica, innovadora, teórica y práctica orientada a la transformación social. Es la sociología ciencia de la sociedad, pero también es ciencia del cambio social. Ella nos permite conocer las leyes de la organización y funcionamiento de la totalidad social. Como ciencia teórica y práctica encara los problemas de la investigación-acción de sus estructuras y de sus elementos particulares que configuran la realidad histórico-social. En otras palabras, es concretización de la sociología aplicada para comprender, explicar e interpretar todos los misterios que nos plantea la sociedad subdesarrollada y dependiente.

Asimismo, nos plantea el gran reto del desarrollo autónomo, a fin de alcanzar un nuevo orden social, es decir, una nueva sociedad diametralmente opuesta a la actual sociedad. Nos adscribimos al desarrollo de una sociología crítica, la cual postula una sociedad justa y equitativa, enteramente humana y humanizada para el Perú, América Latina y el mundo globalizado.

Finalmente, debemos precisar que el presente trabajo tiene dos capítulos fundamentales: el primero, aborda el tema Sociología y sociedad; y el segundo, Sociología y universidad.

El primer capítulo trata de los antecedentes. En el segundo capítulo se analiza específicamente la sociología universitaria.

\section{Sociología y sociedad}

\section{Antecedentes. Difusión de las ideas sociológicas antes de 1896}

El Perú entre 1821 y 1896 muestra el desarrollo de una sociedad colonial-neocolonial, muy heterogénea, con profundos contrastes y desequilibrios estructurales en su formación social. En suma, el Perú evidencia la imagen de una sociedad semi-colonial y sub-capitalista. Esta sociedad en formación muestra obvias dificultades de articulación e integración socio-espacial y socio-cultural. Será en este contexto histórico-social que la difusión y circulación de las ideas sociológicas, al incorporarse a un medio social preeminentemente conservador 
e incipientemente liberal van a operar como elementos corrosivos, críticos, extrańos, probablemente peligrosos. Estas ideas sociológicas serán el topo-social de la modernidad incipiente y que va definiendo una nueva teoría y praxis entre los actores sociales (conservadoresliberales-anarquistas-socialistas). Las ideas sociológicas que circulan en la esfera cultural, sin duda, son un hecho social nuevo e innovador en un medio social conservador y ultra reaccionario.

Dichas ideas sociales se difunden, se mezclan y las encontramos en los debates, en las confrontaciones y luchas teóricas e ideológicas en boga en aquella época. Es decir, entre los liberales y conservadores y elementos de orientación anarquista, socialistas, positivistas y evolucionistas de vieja data. El conjunto de ideas sociales tendrán como centro de irradiación las principales ciudades de este periodo histórico (Lima-Callao, Cusco, Trujillo y Arequipa, principalmente).

Consecuentemente, las ideas sociológicas que se desarrollan en América Latina y en el Perú, son el factor que crean las condiciones y la atmósfera - favorable- a la germinación y fundamentación de la ciencia de la sociedad.

Nos preguntamos: ¿Quiénes fueron los actores y agentes que propiciaron el desarrollo de la sociología en América Latina y en el Perú? ¿Qué medios o mecanismos utilizaron para difundir las ideas y conocimientos sociológicos?

Entre los actores y agentes principales debe mencionarse a la capa de los políticos liberales y conservadores, los periodistas, los profesores universitarios, los lectores de libros, periódicos y revistas, los trabajadores, los artesanos y obreros, etc.

Los medios o mecanismos que utilizaron para difundir sus concepciones, teorías e interpretaciones, fueron: el debate y los discursos parlamentarios, los discursos académicos, la cátedra universitaria, los libros, los periódicos, las revistas, las tesis universitarias, los libros de ensayos o folletos de inspiración y orientación sociológica.

Antes de 1896, los hechos sociales que dan cuenta de la atmósfera sociológica, son los siguientes: se recuerda que en América Latina se desarrolló la primera cátedra universitaria de sociología. Se enseñará en Colombia en 1882 y en Puerto Rico en 1883. En el caso peruano, se nota con mucha claridad la presencia de la sociología a través del discurso académico de Javier Prado y Ugarteche que lleva por título: "Estado social del Perú durante la dominación española” (1884). En este ensayo, se habla del estado sociológico del Perú durante el Virreinato. Así como se reseña los principios sociológicos que hoy forman parte de las ciencias consagradas al estudio del hombre. El autor, además, postula que los estudios de sociología requieren una atención detenida de aquellos fenómenos que el hombre presenta en su relación con la sociedad a que pertenece.

Después de este trabajo aparece otro estudio famoso y de gran valor histórico, por ser de tipo sociológico. Públicamente, aparecieron en 1885-1886-1902. Nos estamos refiriendo a los libros de Joaquín Capelo Sociología de Lima (Libro Primero y Segundo, 1885). El libro Tercero se publicó en 1886. Y, por último, el libro Cuarto se editó en 1902.

Otro trabajo relevante es el ensayo de Carlos Lisson y que lleva por denominación: Breves apuntes sobre la Sociología en el Perú en 1886 (publicado en 1887).

De otro lado, afirma Jorge Basadre que en 1891, con ocasión de la apertura del año académico en la Universidad de Cusco, el médico Antonio Lorena sugirió el cultivo de la nueva ciencia sociológica en el país y trazar las leyes sociales que rigen el desenvolvimiento de los pueblos y de la colectividad nacional (Basadre, Jorge; T.1, 1969, 7).

En síntesis, estos son los prolegómenos que anteceden a la creación de la primera cátedra universitaria de sociología en el Perú.

\section{Creación de la primera cátedra universitaria de sociología en el Perú}

En 1896, en la ciudad de Lima, en la Facultad de Letras, se creó la primera cátedra de Sociología. Para regentarla se designó a Mariano Hilario Cornejo Centeno. Desde esta lejana fecha hasta fines de la década de los ańos 50 del siglo XX, el Curso de Sociología o Sociología General, Sociología Integral, Introducción a la Sociología y Sociología Nacional o Peruana, formó parte de los Planes de Estudio de la Facultad de Letras. La mencionada cátedra de Sociología contribuyó a la formación académica, científica, cultural y profesional, de muchas generaciones estudiantiles de esa Facultad y otras especialidades (Educación, Economía, Administración, Derecho). Ciertamente, la sociología ayudó a reflexionar, comprender, explicar e interpretar científicamente la complejidad de la realidad social. Asimismo, estimuló la necesidad de estudiar e investigar en profundidad los grandes temas o problemas de la sociedad peruana, sus tensiones y sus conflictos sociales. 
La primera cátedra de Sociología inaugurada por Cornejo y los que posteriormente la continuaron, sirvió de modelo para la enseńanza en otras Facultades de Letras de las universidades de provincias de nuestro país (Cusco, Trujillo y Arequipa). Iniciado la enseñanza de la sociología en San Marcos, a continuación le sigue la Universidad San Antonio de Abad de Cusco, en la Facultad de Letras. El curso de Sociología se enseñará, a partir de 1901, bajo la dirección académica del profesor Isaac Azpilcueta.

Luego, a la Universidad de Cusco le sigue la Universidad de Trujillo. En 1902, en la Facultad de Letras, designan al profesor J. Rivadeneira para que imparta conocimientos de Sociología. Cronológicamente, continuará en la enseñanza de la sociología la Universidad de San Agustín de Arequipa, en la Facultad de Letras.

Con relación a la cátedra universitaria, es necesario precisar y ahondar sus antecedentes hasta encontrarnos con la figura del profesor Alberto Fuentes Llaguno, quien enseñó el curso de Sociología General. Hay referencias históricas que señalan que el curso de sociología se imparte desde 1909. Respecto a lo extra académico y lo académico deberá analizarse el papel político e intelectual de dos figuras: Lino Urquieta y Francisco Mostajo. Estudiar sus aportes al pensamiento social, a fin de completar el cuadro histórico-social.

\section{Sociología posterior a 1896}

La institucionalización de la Primera Cátedra de Sociología en la Universidad de San Marcos, sin duda, servirá de modelo a las universidades de provincias: de Trujillo, Cusco y Arequipa, las cuales jugarán un rol cultural en el desarrollo universitario y en el desarrollo urbano-regional.

En general, la sociología estructurada académicamente y dinamizada en nuestra sociedad, tuvo una fuerte influencia europea y norteamericana, difundiéndose las principales teorías predominantes en este periodo histórico-social. También, las teorías sociológicas en boga influirán en la teoría y praxis de los diversos actores y grupos sociales; en las prácticas políticas, académicas y sociales de los individuos y movimientos sociales en las distintas coyunturas políticas. El aporte original de la sociología estará estrechamente ligada al desarrollo del pensamiento indigenista y a las otras corrientes de pensamiento social.

\section{Medios de difusión de la sociología}

\section{a) Parlamento}

Debate parlamentario y luchas políticas. Los discursos parlamentarios, resultan verdaderas fuentes sociohistóricas. La sociología en el Perú y del Perú, es una disciplina estrechamente articulada a la teoría y praxis política. Esta materia adopta la forma de una sociología aplicada o concreta. Por tanto, es muy rica en sus expresiones y manifestaciones como data empírica para efectuar análisis y reflexiones de los procesos y fenómenos sociales del contexto nacional y/o latinoamericano. En efecto, los estudiosos e investigadores deberán analizar sistemática y rigurosamente los libros de debate parlamentario y los discursos políticos parlamentarios. En ese sentido, por ejemplo, estudiar sociológicamente, los documentos siguientes:

- Mariano H. Cornejo: Discursos escogidos y datos biográficos, por Ricardo H. Cornejo (1974)

- Discursos parlamentarios, de Mariano H. Cornejo (10 tomos)

- M. Lino Urquieta. Algunos discursos politicos y parlamentarios, por Miguel A. Urquieta (Arequipa, 1917)

- Discursos parlamentarios, de Roberto Mac Lean y Estenós (1940)

\section{b) Periodismo}

Periódicos y revistas científicas y culturales. En los periódicos y revistas encontraremos, a no dudarlo, artículos interesantes de corte sociológico. Es también una rica fuente sociológica. El examen debe comprender Lima-Callao, Cusco, Trujillo y Arequipa. Sobre el punto, una fuente obligada de consulta es el libro de Carlos Miró Quesada: Historia del periodismo peruano (1957); el artículo "Bosquejo de una sociología integral" de Oscar Miró Quesada (El Comercio, 28-07-1916), etc.

\section{c) Libros especializados de Sociología}

Libros traídos por los libreros, las universidades y los docentes en sus viajes al extranjero. Esta literatura sirvió para cultivar el estudio, la reflexión y la crítica sociológica en nuestro país. En el Perú se conoció y discutió a los clásicos de la sociología: Comte, Durkheim, Marx, Weber, Spencer, Pareto y otros. Ellos subvirtieron el orden espiritual o superestructural, renovando el ambiente conservador de la época de atraso neocolonial. 


\section{d) Discursos académicos}

Este es otro filón sociológico. Tanto en Lima como en provincias con universidades, la apertura del Año Académico era la ocasión propicia para el desarrollo y exposición de una gran y magnífica disertación a cargo de un distinguido y notable catedrático, quien era comprometido para hablar sobre algún tema de actualidad o de interés científico y cultural. Cabe recordar los famosos discursos:

- "Estado social del Perú durante la dominación española", de Javier Prado y Ugarteche. Lima, 1894.

- "Los principios generales de la Sociología", de Mariano $\mathrm{H}$. Cornejo.

- "Las profesiones liberales en el Perú", de Manuel Vicente Villarán, Lima, 1900

- "La crisis presente", de Víctor Andrés Belaunde, Lima, 1914.

- "Discurso académico en la apertura del Año Universitario", de Víctor M. Maúrtua, Lima, 1915.

\section{e) Tesis universitarias y libros de ensayos}

Las tesis y ensayos de naturaleza sociológica, en el contexto nacional, son realmente importantes e interesantes por su contenido científico y por la temática que abordan en lo teórico y en lo empírico de los hechos sociales. Existen tesis de sociología general como "La evaluación de las doctrinas sociológicas", de Salvador Cornejo, analizando las cuestiones siguientes: génesis de la ciencia sociológica, multiplicación de las doctrinas sociológicas: su clasificación, probabilidad de determinar el proceso seguido por el pensamiento sociológico (Lima, 1919).

Otros trabajos que fundamentan y apoyan el desarrollo de una sociología nacional. El autor que sustenta y defiende la necesidad de tener una sociología de este tipo es Ricardo Bustamante Cisneros, en su artículo "Introducción al estudio de sociología nacional" (Lima, 1919).

La sociología aplicada, la práctica el profesor Alberto Ballón Landa, con su tesis "Los hombres de la selva. Apuntes para un ensayo de sociología aplicada" (Lima, 1917), "La sociología de Arequipa" (Arequipa, 1908)

Además, no debemos olvidar los Ensayos de sociología peruana de Luis Guinassi Morán (1908 ), quien hace una presentación de varios temas o tópicos, según su criterio: M. Paul Groussac y la sociología peruana, Objeciones a la inmigración europea, La relación numérica de los sexos según el Censo de 1876 y su signi- ficado sociológico, Intelectualismo y revoluciones de Arequipa, Blancos e indios en el Perú, Cruzamientos de estas razas, China americana, Volviendo a los orígenes, El gran problema, Apéndice: Una polémica sobre la revolución rusa.

\section{Corrientes o tendencias de pensamiento sociológico predominantes}

\section{a) Sociología positivista y evolucionista}

Esta es la sociología que se introduce. Se difunde. Se asimila. Se trasmite mecánicamente. Se repite o se recrea en los claustros universitarios. Es decir, se conoce la sociología de Comte y de Spencer. Este tipo de sociología positivista y evolucionista germina en un medio conservador donde impera el pensamiento escolástico, metafísico y el krausismo. La sociología comteana y spenceriana resulta lo "moderno y progresista”, para aquella época. Pero, en el fondo, es una teoría e ideología conservadora. Dicha sociología proclama el valor y la importancia de la ciencia, la observación, la experimentación y la comparación; igualmente, imagina la sociedad como un organismo biológico y fisiológico. Esta será la cantera teórica del estructural funcionalismo que durará toda la etapa de la cátedra universitaria.

\section{b) Sociología indigenista}

Este es un tipo de sociología aplicada o especializada que se desarrolla en nuestro contexto nacional. El eje fundamental de esta reflexión y teorización sociológica tiene como centro la valoración y reivindicación de los pueblos indígenas o pueblos originarios, explotados, esclavizados y sometidos a un régimen de servidumbre. Son grupos étnicos, discriminados, segregados y marginados desde la colonia hasta la actualidad.

La sociología indigenista se orienta a buscar e interpretar nuestras viejas raíces históricas, sociales y culturales. Es la sociología académica y extraacadémica que contribuye al conocimiento de la problemática del indio o de los pueblos indígenas andino-amazónicas. La masa indígena es un factor social fundamental, en el nuevo proyecto histórico del desarrollo nacional. Es parte esencial en el proceso del desarrollo y cristalización del verdadero Estado-nación a construir por las clases populares en el Perú contemporáneo. Los principales representantes del pensamiento indigenista son: Luis E. Valcárcel (Tempestad en los Andes, 1927 ) y José Uriel García (El nuevo indio, 1930). También 
debe mencionarse a Gamaniel Churata (Arturo Peralta Miranda ), César Vallejo y Antenor Orrego.

\section{c) Sociología anarquista, socialista y marxista}

Es un tipo de sociología que se desarrolla y difunde, principalmente, en el seno de la incipiente clase obrera y en los núcleos artesanales, empleados y estudiantes muy ligados a los movimientos sociales, políticos y culturales.

El anarquismo: tiene su personalidad relevante en Manuel González Prada y en los actores proletarios Manuel Caracciolo Lévano y Delfín Lévano. La teoría y praxis anarquista se concretiza en el periódico La Protesta (1911-1926) y en el movimiento anarcosindicalista. Lima-Callao se convirtió de este modo en el centro principal de irradiación de las ideas y del modelo organizacional ácrata.

En la ciudad del Cusco, antes de 1910, existía ya la presencia de algunos representantes del pensamiento anarquista todavía difuso. Entre ellos pueden contarse a Ángel Gasco, que trajo las ideas anarquistas de Italia y a Manuel Jesús Urbina, estudiante radical y apasionado de la doctrina anarco-sindical (Tamayo Herrera; 1981, 155).

En el norte, en la ciudad de Trujillo, el anarquismo es impulsado por Julio Reynaga y Pascual Meza Véliz y se desarrolla a través de la Liga de Artesanos y Obreros del Perú, de los periódicos La Antorcha, El Pueblo Unido y El Jornalero; asimismo por la labor desplegada por el Centro de Estudios Sociales Unión y Energía (Ramos Rau; 1987, 21).

En cuanto a la ciudad de Arequipa, es importante mencionar los esfuerzos desplegados por los liberales integrados por Francisco Mostajo, Mariano Lino Urquieta, Francisco Gómez de la Torre, Eduardo F. Ferga, Max Guinassi Morán, Victor Ballón y otros. El Ariete, será el periódico difusor de las nuevas ideas (Ballón Lozada; 1992, 120).

El socialismo tiene como figuras históricas a Santiago Giraldo, Carlos del Barzo, Luis Ulloa, Víctor M. Maúrtua y Luciano Castillo. El marxismo creador y aplicado a nuestra realidad tiene como personalidad brillante a José Carlos Mariátegui, quien teórica y metodológicamente desarrolla la sociología marxista para develar científicamente los hechos sociales de la escena nacional y mundial. La teoría y la praxis del Amauta se expresan en Defensa del marxismo, en 7 ensayos de interpretación de la realidad peruana, la revista Amauta y el periódico Labor. El marxismo mariateguista se utilizó para comprender y explicar científicamente la esencia y dinámica de nuestra formación social.

\section{d) Sociología populista-aprista}

Esta sociología de raíz nacional y latinoamericana postula desarrollar un pensamiento original y autónomo e indoamericano. Víctor Raúl Haya de la Torre es el teórico e ideólogo de esta corriente de pensamiento social. $\mathrm{Su}$ pensamiento sociológico modular lo encontramos en el libro Antimperialismo y el Apra; y, en general, en sus obras completas.

El aporte de Haya de la Torre es entender la realidad para transformarla, con propuestas y soluciones propias, movilizando a las masas populares (clase media, obrera y campesina).

\section{e) Sociología social-cristiana}

Esta sociología de la peruanidad, también postula, en su teoría y praxis, conocer y producir el cambio social de la sociedad peruana. Víctor Andrés Belaunde es la figura representativa de esta tendencia de pensamiento social. Su contribución teórica y de interpretación de nuestra sociedad lo encontramos en Realidad nacional, Meditaciones peruanas y Peruanidad; además, en la revisión y análisis de sus obras completas.

\section{Sociología y universidad}

La enseñanza de la sociología en San Marcos.

\section{a) El programa de Mariano $\mathrm{H}$. Cornejo}

La enseñanza de la sociología de Cornejo se puede inferir del contenido de su libro Sociología general en dos tomos (1908)

Sociología general tiene la siguiente estructura temática:

- Primer Tomo

Introducción

Capítulo 1. Formación de la sociología

Capítulo 2. Teoría de la evolución

Capítulo 3. El método

Sociologia General

Capítulo 1. Los primeros hombres

Capítulo 2. La adaptación y la solidaridad

Capítulo 3. La sinergia social y la organización de los grupos 
Capítulo 4. La sociedad y el progreso

Capítulo 5. Factores sociales

Capítulo 6. Factores externos

Capítulo 7. La herencia

Capítulo 8. Raza

Capítulo 9. La población

Capítulo 10. Imitación y educación

Capítulo 11. División del trabajo

Capítulo 12. La guerra

- Segundo Tomo

Sociologia General

Capítulo 13. Lenguaje

Capítulo 14. Mito y religión

Capítulo 15. El arte

Capítulo 16. La costumbre, el Derecho y la Moral

Capítulo 17. Matrimonio y familia

Capítulo 18. El Estado

Capítulo 19. La Ciencia. Conclusión

El concepto de sociología en Cornejo

El objeto de la sociología: es el estudio positivo, es decir, científico de la sociedad (T. 1, 103 ). Respecto a la sociología, argumenta lo siguiente: Si la sociología es una ciencia en su infancia, esa infancia es robusta y bien desarrollada. Los principios fundamentales de la ciencia están perfectamente establecidos; sus cuadros bien definidos, son capaces de recibir y sistematizar todas las observaciones. La sociología en su estado actual nos revela no sólo las formas en que se cristaliza la vida colectiva, la familia y el Estado, sino sobre todo, el desenvolvimiento de la conciencia humana; nos muestra el proceso gradual que coordina los sentimientos y el pensamiento dentro del marco del lenguaje, del mito y la moral; nos descubre el pensamiento universal de adaptación que domina la totalidad de la vida colectiva, con sus funciones y estructuras, y que produce su más elevado esfuerzo de correspondencia subjetiva, el conocimiento sistemático de la realidad, o sea la ciencia, la pretensión de explicar y de prever, de corregir y completar conscientemente la obra de la obra de la naturaleza y de la historia.

En suma, la sociología constituye el noble esfuerzo de demostrar que traspasando los límites de las formas animales, el fenómeno vital y psíquico se organiza en un agregado colectivo y en una conciencia común, obedeciendo al determinismo universal, traducido por las leyes fundamentales de continuidad y de correlación, que en los fenómenos orgánicos y sociales corresponden a la sucesión y a la coexistencia, que son los caracteres de la realidad, del fenómeno del ser, concebido en sus relaciones con el tiempo y el espacio. Cornejo, finaliza su explicación teórica, indicando que su trabajo no ha intentado aportar datos nuevos, sino simplemente presentar las que consideramos aspiraciones de la ciencia sociológica; no pretende resolver, sino estimular el estudio de sus problemas; avivando la fe en la posibilidad de su resolución ( T. 2, 543-545)

\section{Su noción de sociedad}

El concepto de sociedad, dice Cornejo, nos da la idea de un todo así como el de organismo. Pero las partes que lo forman necesitan, sin duda, de puros caracteres. Los fenómenos sociales no se producen en un montón de piedras ni en el sistema solar, donde falta la espontaneidad de la vida. Así es que sólo un conjunto de seres vivos forman una sociedad y un organismo (T. 1, 186).

\section{Los hechos sociales}

Nosotros creemos, sostiene Cornejo, que los hechos sociales se pueden definir con más propiedad diciendo que son los modos de hacer, fijos o no, que impone el sentimiento de solidaridad (T. 1, 188).

\section{El concepto de clases sociales}

El profesor aclara que, lo que lo distingue una sociedad civilizada de un grupo salvaje es la diversidad círculos: pensadores, hombres de Estado, sabios, administradores, militares, industriales, pedagogos, agricultores, obreros, constituyen clases, que sucesivamente se asimilan nuevos elementos que adquieren su espíritu corporativo y se identifican sus intereses (T. 1, 86).

\section{Elite y sociedad}

Cornejo explica que, el interés de una sociedad está en tener una gran mayoría moral y laboriosa, consagrada a la industria, y solamente una minoría intelectual de espíritu superior, de cultura profunda, que constituye un núcleo directriz para todas las ramas de la actividad (T. 1, 449).

\section{Diferenciación de clases}

En cuanto a este concepto, dice Cornejo, que la corporación, la clase y la casta representan grados de diferenciación: la casta es una forma transitoria; la clase es inseparable de la jerarquía; la corporación es una forma permanente (T. 1, 461). 


\section{Conflictos sociales y los antagonismos}

Según el académico, los conflictos sociales pueden ser violentos o pacíficos. $\mathrm{Y}$, los resultados del conflicto pueden ser, en unos casos, la destrucción o transformación de la individualidad, de la totalidad del agregado; y en otros, solamente la destrucción o transformación de una parte, de una facultad o de un modo de acción (T. 1, 170).

En cuanto a los antagonismos sociales, señala que la vida social se desarrolla junto a deseos que llevan al acuerdo, otros que conducen al antagonismo (T.2, 518).

\section{Complejidad de la realidad social}

Es consciente, el cultor de la sociología, que la realidad resulta siempre más rica y variada que todas las teorías y las hipótesis (T. 2,526$)$.

\section{Referencia a la teoría marxista}

Los socialistas, precisa Cornejo, han contribuido a fijar la importancia del factor económico en la evolución social. Su representante científico es Marx. De otro lado, enfatiza que siguiendo a Marx, Mohl, Cerey, Berenstein, Vandervelde, Loria, Beneit, Malon, Vacherot, todos los socialistas; y los economistas como Wagner y Schmoller, han estudiado la evolución económica, cuya influencia preponderante, sino única, está hoy científicamente reconocida (T. 1, 34).

\section{b) El Programa de Carlos Wiesse}

Para una mejor comprensión, hemos ordenado y simplificado el programa analítico del Curso de Sociología de Wiesse.

\section{Extracto de Sociología (1908)}

\section{Parte Preliminar}

Capítulo 1. Concepto de Sociología

- Objeto de la Sociología

- Ciencias Sociales Particulares

- La Sociología, ciencias independientes

- Relaciones de las CC.SS

- Definición de la sociología

Capítulo 2. Historia de la Sociología

2.1 Historia de la Sociología

- Fundación de la Sociología: A. Comte

2.2 Doctrinas Sociológicas

- Sociología mecánica

- Sociología Etno-antropológica
- Sociología geográfica

- Sociología Bioanalógica

- Sociología basada en la Psicología

- Sociología basada en las CC.SS

- Materialismo Histórico (Concepto de los materialismos históricos con las doctrinas Sociológicas)

Capítulo 3 Los problemas de la sociología

Capítulo 4 El método de la sociología

4.1 Métodos

4.2 Procedimientos

4.3 Plan del Curso

- Análisis del proceso social, o estudio de la naturaleza de la sociedad como combinación de fuerzas sociales

- Eras del proceso o evolución social

- Sistema de problemas éticos que constituyen el proceso social

Sociología General

Capítulo 1. Análisis del proceso social

La base física de la sociedad

- Alma y cuerpo de la sociedad

- Ascendente del hombre sobre la naturaleza

- Herencia y medio físico

- Situación geográfica

- Razas

Capítulo 2. Elementos del proceso social

- Los intereses

- Los individuos

- Intereses constitutivos del individuo

- Evaluación del individuo

Capítulo 3. Fenómenos sociales subjetivos

- Concepto del medio espiritual-sociológico

- Fenómeno de la diferenciación

- Formación de grupo

- Fenómeno del conflicto

Capítulo 4. Estructura y funciones sociales

- Estructura social

- Fenómenos sociales

- Las fuerzas sociales

- Conciencia social

Capítulo 5. Fenómenos objetivos de la sociedad

- Aspecto de la colectividad

- Pluralidad o multiplicidad de los individuos

- Solidaridad o comunidad

- Aspecto de la individualidad (individualidad y socialización)

Capítulo 6. El proceso social considerado como sistema de problemas psíquicos

- Explicaciones Preliminares 
- Los elementos de la causación social

- Problemas iniciales de Psicología Social

\section{Wiesse y la definición de la sociología}

Este profesor sostiene que la sociología, en el pensamiento de su fundador Augusto Comte, es la ciencia de la estructura y de las funciones de la sociedad. Herbert Spencer la llamó de la evolución superorgánica. Para Ardigó, tiene por objeto la constitución de la sociedad civil y, de consiguiente, la justicia que es su función característica. Durkheim la define como la ciencia de las instituciones, de su génesis y de su funcionamiento. Palante considera que no es más que psicología social, la cual estudia la mentalidad de las unidades reunidas por la vida social. Ward señala que es la ciencia de las funciones sociales. Smol dice que es el estudio de los hombres modificados o transformados por la asociación. Rousiers indica que las ciencias sociales tiene por objeto el estudio de los fenómenos sociales por el método de la observación. Groppali, a su vez, dice que es la filosofía particular; la cual se propone estudiar los límites y las condiciones cognoscitivas de los hechos sociales ; trata de coordinar los resultados más generales de las ciencias sociales particulares.

¿Para Wiesse qué es la sociología? Es la ciencia que tiene por objeto el estudio del proceso de la asociación humana, analizando el proceso social de la evolución social, así como los problemas éticos y técnicos (Wiesse, $1908 ; 15,16,90)$.

\section{Concepto de sociedad}

La sociología estudia el proceso de la asociación humana y, al mismo tiempo, observa las formas sociales con su contenido, sus consecuencias y sus causas. De otro lado, afirma: donde existe sociedad hay estructura y función social (Wiesse, 4, 160).

\section{El hombre ser social}

Cada individuo, dice el autor, nace dentro de las relaciones humanas. Desde el tiempo de Aristóteles el hombre ha sido considerado como un ser social por naturaleza; pero esto nada explica. Deben existir, sin duda, condiciones innatas para la asociación (Wiesse, 151).

\section{Estructura social}

Considera que la noción de estructura ha desempeñado un gran papel en las ciencias sociales y debe siempre emplearse, pero reduciendo la razón de su preeminencia a proporciones menores. Esta noción significa una estructura de partes relacionadas con las actividades. El término estructura social se aplica al hecho esencial, de que cuando los hombres actúan juntos, sea por parejas o en muchedumbre, existe siempre una armonización de alguna especie entre ellos. Siempre que se producen actividades sociales, esta manera de armonización entre los actores, ésta estructura de partes, es tan efectiva como la existencia de las partes mismas (Wiesse, 157, 158).

\section{Individuo y sociedad}

En este punto debemos, pues, partir de las bases de que el individuo, tomado como unidad social, refleja a la sociedad y, a su vez, la sociedad refleja al individuo. Pero, en sociología, el individuo que conocemos no está aislado, sino que se halla con conexión de varias maneras con uno o más individuos (Wiesse, 138).

\section{Individuo y conciencia}

Cada individuo comienza siendo un repertorio de sentimientos, nociones, ideas, prejuicios, creencias, teorías, propósitos, tan pronto aparece ser consciente (Wiesse, 176).

\section{El grupo sociológico}

El término grupo sirve para designar sociológicamente a cualquier número de gentes, grande o pequeño, entre quienes se descubre relaciones de tal naturaleza, que nos vemos obligados a concebirlos en conjuntos. El grupo sociológico puede definirse del modo siguiente: grupo es un número de personas cuyas relaciones mutuas impresionan en el mismo grado en que la atención se encuentra atraída. El grupo viene a ser la condición universal de la asociación, porque las gentes viven siempre en grupos (Wiesse, 141).

\section{El quehacer de la sociología}

El propósito de la sociología es determinar las formas y los modos de las relaciones entre los hombres (W., 143).

\section{La investigación sociológica}

Para Wiesse el orden apropiado del procedimiento del punto de vista sociológico de aproximación, es el análisis de las situaciones sociales (W., 241).

\section{Acerca del materialismo histórico}

Como el socialista Karl Marx, cuya obra principal Das Kapital, se considera por sus adversarios como libro 
original y notable, se inicia la corriente del materialismo histórico, dirigida a someter la historia al determinismo universal con leyes y factores causales que se desentrañan con criterio vastamente comprensivo, radicalmente objetivo, orientado siempre al sentido económico.

El materialismo histórico y las doctrinas sociológicas. El profesor, menciona a Asturiano, señalando que éste ha sido el representante más perfecto y reciente de la filosofía sociológica, si bien limitada a la historia. En análisis comparativo, se afirma que el materialismo histórico tiene sobre el sistema de Comte la enorme ventaja de partir de la verdadera base de la pirámide social, de la estructura y de las actividades económicas, mientras que Comte por un error que parece ser inexplicable había comenzado por la cima, es decir, por las creencias religiosas y científicas, pretendiendo explicar con su orientación las grandes transformaciones de la política, del derecho y hasta de la economía, y cayendo así en absurdos análogos a aquéllos en que habían incurrido los biólogos, si hubiesen tomado por base las formaciones orgánicas el cerebro anterior de los animales más elevados (Wiesse, 66).

c) Programa analítico del Curso de Sociología, de Roberto Mac Lean y Estenós (1936)

Capítulo 1

- El contenido de la sociología

- Amplitud de los estudios sociológicos

- Causas internas (el sentido de la palabra sociología, el desarrollo de los sociólogos)

- Causas externas (el contenido de las otras disciplinas sociales, la realidad del problema )

- El método sociológico

- Discrepancias de los sociólogos

- Spencer y el método de las ciencias matemáticas: la deducción

- Proceso deductivo de las leyes generadoras de la evolución universal al complejo social

- Bacon, Asturaro y el método de las ciencias físicas y biológicas: La inducción

- Ascenso del hecho social a la ley que debe regirle

- Durkheim y Spengler: El método comparativo

- Conocimiento de las causas de los fenómenos sociales por la comparación de su desarrollo, a través de todas las épocas históricas

- Comte y el método casual inverso

- El método histórico de Stuart Hill
- Aplicación del método directo de la sociología pura y del método sociológico de Stuckemberg

- La sistematización constructiva en sociología

- Sus tres aspectos (la unidad del conocimiento, la depuración de los sistemas, la sociología integral)

- Estudio científico de la sociología (el análisis y la síntesis en la explicación unitaria de la realidad social)

- Leyes sociológicas

- Negación de la existencia de las leyes sociales

- Comte y su ley del desarrollo de la humanidad

- Intentos de aplicar a la Sociedad las leyes biológicas, psíquicas y los principios de la estadística

- Las leyes propias de la sociología

- Su proceso: Observación de los hechos sociales; abstracción de sus caracteres comunes y enunciación de los principios generales

- Clasificación de las leyes sociológicas

- Leyes propias de la sociología (Ley de la causalidad, ley del desarrollo, la evolución, el progreso)

- Eficacia de las leyes sociales

- Relaciones de la sociología con las demás disciplinas conexas

- La sociología y la filosofía de la historia

- La sociología y la historia

- La sociología y la moral

- Relación de la sociología con la economía política, el derecho, el arte, la estadística, la antropología, la geografía social y las demás disciplinas conexas.

- Las escuelas sociológicas

Reseña histórica de las diversas interpretaciones del complejo social

- Época pre-comteana (interpretación del fenómeno social en la antigüedad y en la edad media; interpretación metafísica del fenómeno social; la escuela apriorista del fenómeno social; la escuela histórica del siglo XVII, el criterio ideológico de la constitución social; los precursores de la sociología)

- Época comteana (Comte, fundador de la sociología; la sociología estática, la sociología dinámica, la clasificación de las ciencias, la evolución como desenvolvimiento del orden)

- Época post-comteana (sociología biológica, interpretación spengleriana, sociología psicológica, la antroposociología, la sociología geográfica, interpretación estadística de la sociedad)

- La orientación socialista (lucha constante de dos fuerzas antagónicas, burguesía y proletariado, ori- 
gen del movimiento socialista, el ideal anarquista, el comunismo, el socialismo, historia del socialismo, el socialismo utópico, el socialismo científico, el socialismo cristiano, el socialismo radical, el socialismo agrario, el socialismo y el régimen incaico, el socialismo resultado de la evolución histórica, el socialismo ideal de emancipación y anhelo perenne de mejoramiento social; la revolución social, la revolución francesa, la revolución rusa: Lenin, Trotsky y Stalin, el porvenir socialista

- El movimiento sociológico contemporáneo (sociología norteamericana, inglesa, alemana (Hegel, Dilthey, Simmel, Marx y Von Stein, Weber) Capítulo 2

- La evolución social

- El origen de la vida a la aparición de la especie humana

- Razas primitivas

- La sociabilidad animal. Los primeros agregados humanos

- La evolución de los grupos humanos

- Actividades de los primeros grupos humanos

- La ciudad

- El estado

- Proceso subjetivo en la organización de los grupos

- La sinergia social

- El régimen de castas (el sacerdote, los guerreros, el comercio, la industria, el proletariado)

\section{Capítulo 3}

- Exégesis de la evolución social en el Perú

- Época pre-colombiana (Los primeros agregados humanos; teoría de la inmigración Atlántida; teoría de la inmigración asiática; condición salvaje de los primeros peruanos: Cieza de León; El hombre peruano cavernario; El hombre del Tiahuanaco; Influencia de la cordillera andina en las culturas aborígenes; los mitos; trayectoria social del ayllu al imperio; creencias religiosas; las supersticiones; la multitud incaica; el Inca y la multitud; el valor social de los ayllus).

- Época de la conquista y el Coloniaje (La conquista del Perú; la ciudad española en el Perú; la multitud religiosa; los conventos; Inquisición; desigualdad económica y social).

- Época de la Independencia (El aporte de la multitud de la ciudad y del campo en las luchas por la emancipación; multitudes patrióticas).

- Influencia antropológicas en el proceso republicano (La incultura cívica; el caudillismo militar; nue- vas inquietudes sociales).

- El Perú contemporáneo (Tribus salvajes; núcleos civilizados; el problema indígena; las comunidades; la nacionalidad).

\section{Capítulo 4}

- Fuerzas sociales internas: el sexo y el espíritu colectivo

- Fuerzas sociales: el medio físico

- El sexo ( Valor sociológico de los sexos; concepción freudiana del sexo; sexo y religión; el sexo y la trayectoria de la civilización; la promiscuidad primitiva; acción social del hombre; acción social de la mujer; el sexo y la población; el sexo y la herencia; instituciones sexuales; la prostitución; la prostitución en el Perú).

- El espíritu colectivo (El alma colectiva; el lenguaje; el arte; la moral; el derecho).

\section{Contenido de la sociología}

Para Mac Lean y Estenós, la sociología abre sus horizontes en un área muy vasta, pero no bien delimitada. Causas internas y externas determinan la incertidumbre de su contenido. Las primeras, que radican en su propio organismo, son: el significado del vocablo "sociología" y el desacuerdo entre los sociólogos. La segunda está en el contenido de las demás ciencias sociales. El vocablo "sociología” fue creado por Augusto Comte (1798-1857), padre del positivismo, quien lo usó por primera vez en el tomo IV de su filosofía positiva, escrito en 1838.

Con un abolengo etimológico en el que se confunden las raíces griegas y latinas, el vocablo de Comte designó un conjunto de problemas e investigaciones que, hasta entonces, se agrupaban bajo la denominación de "Física Social", término ambiguo que ensayaba expresar la influencia atribuida, en esa época, a la vida física en el desarrollo colectivo.

El barbarismo de Comte fue objeto de duros ataques que se iniciaron en torno a su etimología y que acentuándose llegaron a dudar de la eficacia de la disciplina a la que servía la etiqueta. Lester Ward intentó reemplazarlo por la voz "Socionomía", es decir dominio de las leyes sociales. Se ensayó también enfrentarle muchos otros términos como "Filosofía Social", "Ciencia Social", "Historia natural de la Sociedad"pero ninguno de ellos pudo sustituir al que, con tanto acierto, había creado Comte. Aceptada, después de no pocos esfuerzos, en el lenguaje corriente, la incorporación de la palabra "sociología" al vocabulario científico, 
como una disciplina sustantiva, enlace metódico de los fenómenos humanos, no se verifica sino después de que Spencer en sus libros "Estudios de la Sociología" (1870-1896) y “Principios de Sociología” (1876-1896) investiga y comprueba su necesidad y sus ventajas.

En resumen: En nuestro Siglo el término sociología ha obtenido su filiación definitiva al conocimiento mundial. En Francia, con los cursos de Tarde y de Durkheim, la función del Instituto Internacional den Sociología (1893) y la publicación de la Revista de Sociología (1894) ; en Italia, con la edición de la Revista Italiana de Sociología (1897) y la creación de diversos cursos universitario ; en Bélgica, con una Universidad dirigida por De Greef y estructurada sobre bases sociológicas ; en Alemania con los cursos de Simmel en Berlín y Barth en Leipzig ; en los Estados Unidos con numerosas asignaturas de Sociología en universidades, colegios y seminarios y la edición de varias revistas ; en España y en la América Latina con sendas cátedras de sociología en sus centros de cultura superior (RME, 1938, 9-10).

En América Latina, el hecho más significativo -según Poviña- que en el orden histórico-sociológico ha tenido lugar ha tenido en Colombia, es la inauguración oficial de la primera cátedra de sociología. Fue un 1882 antes que en Chicago, que lo hizo 1892. Su primer profesor fue Salvador Camacho Roldán, quien pronunció el primero de diciembre, con motivo de la clausura de las actividades universitarias, un discurso acerca del estudio de la sociología (Poviña,1959; 227). Es importante recordar, también, que en Puerto Rico Eugenio María de Hostos (1839-1903), fue quien impartió en 1883 un curso de sociología. En tal ocasión dictó algunas notas a sus alumnos, las mismas que fueron publicadas en Madrid, en 1904, bajo el título "Resumen de la sociología" y como Libro III de su Tratado de Sociología. Esta última obra fue publicada tal como la recogieron de labios de Hostos sus discípulos de 1901 (Echánove,1965; 308).

\section{¿Qué estudia la sociología?}

La sociología estudia las realidades sociales, palpitantes y vivas, como una multitud, una revolución, un movimiento vital o latente, cristalizadas en las instituciones, en el temperamento o en la conducta de la colectividad. La sociología es el total de las ciencias sociales. Da la visión panorámica que les falta a éstas. La sociología es, de toda suerte, la filosofía de las ciencias sociales particulares o, dicho con más propiedad, la disciplina que estudia la esencia, órganos y funciones del complejo social, su desenvolvimiento y sus leyes, descubriendo la uniformidad dentro de la constante variación de los fenómenos sociales, revelando la acción recíproca y concomitante de unos sobre otros y de todos en su conjunto, y admitiendo la posibilidad de poder aplicar esas leyes descubiertas a la aceleración del ritmo colectivo y del bienestar social (RME, 1938, 16).

\section{Individuo, grupo y sociedad}

Una sociedad está compuesta de individuos. Ellos integran la primera realidad objetiva que aparece en un grupo social. Todos los agregados sociales se presentan así "formados por una pluralidad de conciencias individuales actuando y reaccionando unas sobre otras". El hombre puede ser considerado como un individuo y como un ser social. Apreciándolo como individuo, compruébase en él, un primer orden de fenómenos de naturaleza psíquica. Las relaciones de los distintos individuos entre sí, acredita un segundo orden de fenómenos de naturaleza interpsíquica. Empero, el hombre es también un ser social. Vive dentro de un grupo y siente su influencia. Por último, debe indicarse que, un conjunto de acciones y reacciones entre el grupo y el individuo o entre los distintos grupos entre sí, dan lugar a una tercera categoría de fenómenos de naturaleza social, cuyo estudio es el objeto de la sociología (RME, 1938, 16-17)

\section{Las leyes sociales}

Roberto Mac Lean y Estenós tiene la concepción teórica de que los hechos sociales no se producen al azar. No son frutos de la casualidad, ni se desenvuelve caóticamente. Obedece, antes bien, a causas que varían en el espacio, en el tiempo y en la psicología humana, siendo posible, por tanto, encontrar en la multiplicidad de los acontecimientos, un núcleo de motivos generadores, un orden en el desenvolvimiento, una ley de desarrollo. En otros términos, existen leyes sociales que presiden la evolución de los pueblos. Concluye, afirmando que a los sociólogos les corresponde descubrirlas, enunciarlas o investigar su cumplimiento. Mac Lean y Estenós, explica el funcionamiento de las siguientes leyes: del desarrollo, de la causalidad, de la evolución o progreso, de la sucesión o de la continuidad, de la complejidad, del paralelismo, de la unidad, de la finalidad general o de las causas finales. La eficacia de las leyes sociales, aunque cierta, debe ser relativa. Error profundo sería creer y admitir lo contrario (RME, 1938, 22-26). 
El Estado y las clases sociales

Es innegable la influencia de las clases sociales en la constitución del Estado. Las clases conquistadoras -patricios romanos y señores del feudalismo medioeval- formaron estados militares. Los nobleza guerrera constituyó despóticamente la familia y se adueñó por la fuerza de la propiedad, dio al Estado, en alianza con el sacerdocio su forma militar y teocrática. Más adelante, la nobleza de la fuerza pierde su poder con el posterior desenvolvimiento de los otros elementos sociales. La burguesía, formada por antiguos plebeyos y hombres libres enriquecidos en la industria o el comercio, reclama para sí el honor de iniciar las reformas liberales que han de quitarle al Estado todo sello autoritario y despótico que le dieran sus fundadores. $\mathrm{Y}$ una que los trabajadores manuales, los antiguos siervos, no han logrado conquistar el poder, constituyen una clase perfectamente organizada cuya influencia ha dejado sentirse en el mecanismo político, persiguiendo la supresión de todos los privilegios y la igualdad social (RME, 1938, 179).

\section{Las élites}

En el desarrollo de las colectividades se comprueba invariablemente, la existencia de una élite, clase social que se destaca por su inteligencia, capacidad y carácter y cuya superioridad para constituir un grupo dirigente se supone, admite o reconoce.

¿Qué élites distingue? La élite obrera, los técnicos, las élites administrativas, las élites intelectuales, las élites deportivas (RME, 1938, 209-211).

En síntesis, toda esta etapa del desarrollo de la cátedra universitaria que culmina en la década de los ańos 50, deberá completarse con el papel de los maestros: José Mejía Valera, Aníbal Ismodes Cairo y Jesús Véliz Lizárraga y algunos otros. Luego, estudiar la creación del Departamento de Sociología para formar a científi- cos y profesionales de la sociología. La etapa científica $y$ profesional, es una etapa que debe ser evaluada y hacer una balance crítico, ponderando equilibradamente sus logros y conquistas. Pero, también, sus frustraciones y limitaciones. Es la tarea pendiente.

\section{Referencias bibliográficas}

Agramonte, Roberto (1963). Sociología latinoamericana. Universidad de Puerto Rico. Río Piedra: Editorial Universitaria.

Aricó, José (1980). Marx y América Latina. Lima: CEDIP.

Basadre, Jorge (1981). Historia de la República del Perú. Lima: Editorial Universitaria. Lima, 1961. T. 1; y, Peruanos del Siglo XX. Ediciones Richay Perú.

Carnero Checa, Genaro (1985). La acción escrita, José Carlos Mariátegui, Periodista (Ensayo). Lima: Centro de Documentación Andina.

CONCYTEC-SOPHICYT (1986). Estudio de historia de la ciencia en el Perú. Vol. II. Ciencias Sociales. Lima.

Denegri Cornejo, Hugo (1966). Mariano H. Cornejo. El hombre y su obra. Lima,

García Salvatecci, Hugo (1990). Visión de un apóstol. Pensamiento del Maestro González Prada. Lima: Emisa Editores.

Hernández Urbina, Alfredo (1976). Compendio de sociología peruana. Lima: Ediciones Raíz.

Ismodes Cairo, Aníbal (1959). Lecciones de introducción a la sociología. Lima: Bib. Sociedad Peruana de Sociología.

Murillo Garaycochea, Percy (1976). Historia del Apra 1919-1945. Lima: Editor Enrique Delgado Valenzuela.

Poviña, Alfredo (1959). Nueva historia de la sociología latinoamericana. Ediciones ASSANDRI. Imprenta Universidad de Córdoba (R.A.).

Salazar Bondy, Augusto (1965). Historia de las ideas en el Perú contemporáneo. Lima: Fco. Moncloa Editores S.A., T. 1 y 2. 
ROGER IZIGA NÚÑEZZZ

\section{Anexo gráfico}

Teóricos sociales occidentales
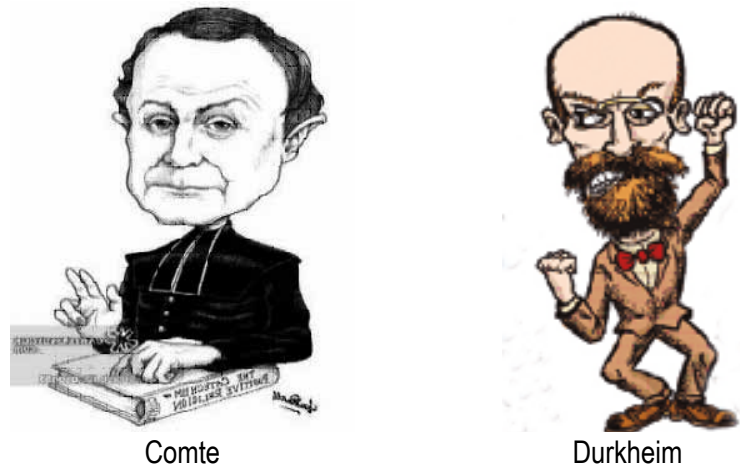

Durkheim

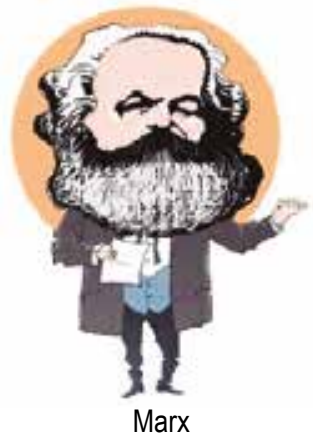

Utopistas

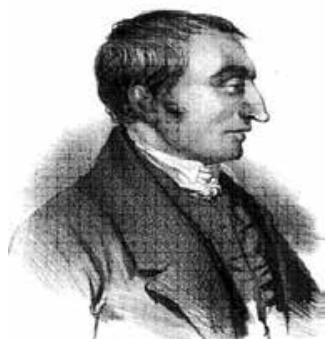

Saint Simon
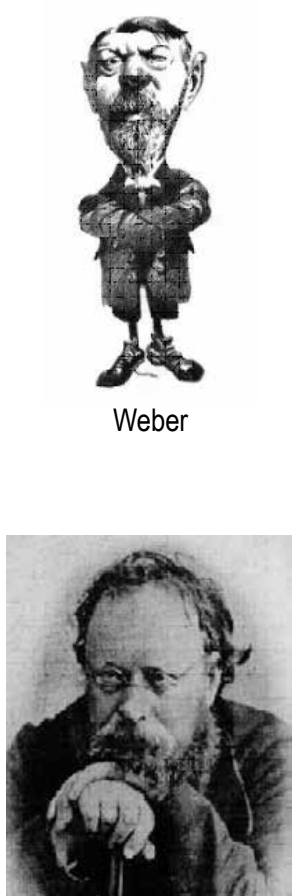

Proudhon
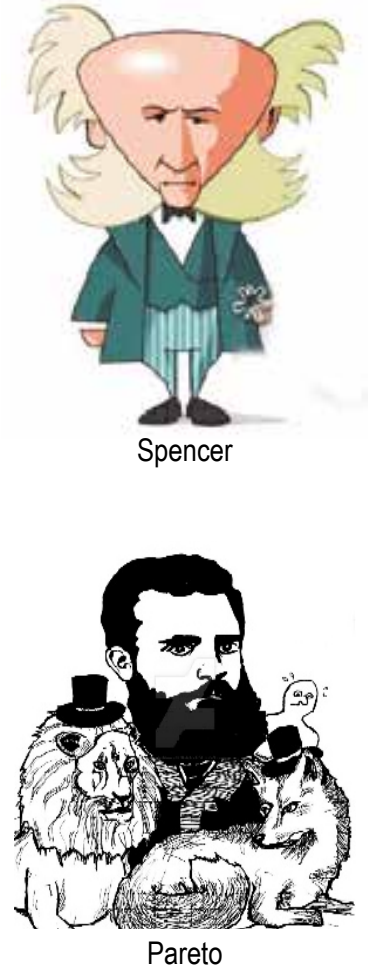

Pensadores sociales peruanos

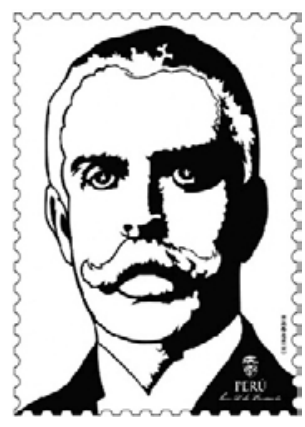

González Prada

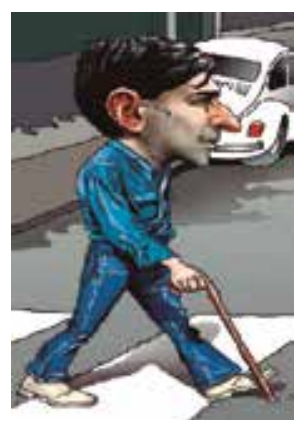

Mariátegui

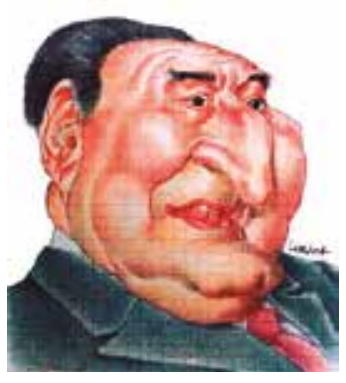

Haya de la Torre

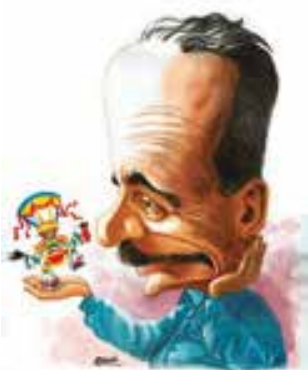

Arguedas 